\title{
Ultrasound is Effective to Treat Temporomandibular Joint Disorder
}

\author{
Shuang $\mathrm{Ba}^{\mathrm{I}}$ \\ Pin Zhou ${ }^{2}$ \\ Ming Yu (iD) \\ 'Department of Ultrasound, The First \\ Affiliated Hospital of Kangda College of \\ Nanjing Medical University, Lianyungang, \\ People's Republic of China; ${ }^{2}$ Department \\ of Stomatology, The First Affiliated \\ Hospital of Kangda College of Nanjing \\ Medical University, Lianyungang, People's \\ Republic of China
}

Background: Temporomandibular joint disorder (TMD) affects millions of people. It is unclear if low intensity ultrasound (US) is effective to treat TMD.

Methods: A total of 160 patients with TMD were enrolled in this study. The subjects were randomized into two groups to receive US therapy or no therapy. Patients in the US group were given US therapy once a day for 5 days per week for 2 consecutive weeks. Before and 4 weeks and 6 months after the treatments, the patients were assessed for pain using visual analog scale (VAS) and the maximum pain-free inter-incisal distance (IID). In addition, mandibular movement (MM), jaw noise (JN), disability index (DI) and craniomandibular index (CMI) were also assessed.

Results: Compared with the patients before the therapy, VAS, IID, MM, JN, DI and CMI in the US group were significantly improved 4 weeks and 6 months after therapy. However, 6 months after the therapy, US group had a recurrence rate of $2.63 \%$.

Conclusion: US therapy can significantly reduce the pain, and improve the functionality of the temporomandibular joint and mouth opening limit for TMD patients, and is therefore recommended for TMD patients.

Keywords: temporomandibular joint disorder, pain, ultrasound, exercise therapy, recurrence

\section{Introduction}

After odontogenic pain, temporomandibular disorder (TMD) is one of the most common causes of pain in the mouth and face, affecting millions of people. ${ }^{1,2}$ It often leads to persisting (chronic) pain that lasts for years. ${ }^{3}$ The conditions affect the masticatory musculature, temporomandibular joint (TMJ) and associated structures. ${ }^{4}$ The most common and typical symptoms of TMD include clicking of joint, mouth opening limitation, muscle and joint pain. The pain can be myogenic, arthrogenic or mixed types, ${ }^{5}$ and can be associated with other chronic pain conditions, including migraine, fibromyalgia, and widespread pain. ${ }^{6,7}$ The disorders are also known to be comorbid with bruxism, irritable bowel syndrome and chronic fatigue, leading to considerably reduced quality of life. , $^{89}$

A number of studies have investigated the efficacy of physical therapies for TMJ pain. These therapies include massage, electrotherapy, physical and exercise therapies $^{10-12}$ as well as biobehavioral intervention. ${ }^{13}$ Among them, extracorporeal shockwave (ESW) therapy is demonstrated to be effective to reduce the pain and improve the mouth function. ${ }^{14,15}$ However, this treatment is relatively slow in relieving pain for patients and needs additional functional therapy to preserve the long-term therapeutic result. ${ }^{15}$
Correspondence: Ming Yu Department of Ultrasound, The First Affiliated Hospital of Kangda College of Nanjing Medical University, 182 Northern Tongguan Road, Lianyungang, 222002,

People's Republic of China

$\mathrm{Tel} / \mathrm{Fax}+8651885605472$

Email ultrasoundhappy@I63.com 
Ultrasound (US) has been studied for treating temporomandibular joint osteoarthritis (TMJ-OA) ${ }^{16}$ and hypoxiainduced chondrocyte damage in temporomandibular disorders, ${ }^{17}$ since it is recognized as a stimulator if used at lowintensity level, and would promote neovascularization, differentiation of mesenchymal stem cells and local release of angiogenic factors that action on ischemic tissues due to improved blood flow. ${ }^{18-20}$ Some preliminary studies show that US is effective in treating TMJ disorders and relieving pain, particularly if it is used in combination with an ice bath. ${ }^{21}$ However, a better understanding of the therapeutic effects is still required for rational and effective use of this therapy for TMD.

In this study, we investigated the therapeutic effects of US on pain and the findings may provide better management of the disease.

\section{Materials and Methods Ethics Statement}

This study was approved by the research ethics committee of the First People's Hospital of Lianyungang, Lianyungang, China (approval number: PHL 3611) and was performed in accordance with the principles set forth in the Helsinki Declaration. Written informed consents were obtained from all patients before treatment.

\section{Trial Design}

This was a randomized trial for US therapy and control.

\section{Participant}

A total of 160 consecutive TMD patients treated at this center between June 2014 and December 2018 were included. Participants were included if they were aged between 18 and 68 years old and were diagnosed having continuous bilateral myofascial pain with visual analog scale (VAS) $\geq 2$ for at least 3 months with or without mouth opening limitation according to the Diagnostic Criteria for TMD. ${ }^{22}$ Subjects were excluded if they had acute trauma, polyarthritis, joint infection, surgical treatment, physiotherapy, splint therapy, or acupuncture within the 4 months before the study, depression and other mental problems, respiratory disease and other diseases that might impact the outcome assessments. Patients were also excluded if abnormal findings were found in routine physical and laboratory examinations. They were asked to avoid pain-relief medication or muscle relaxants for at least 3 days before the evaluations and during the treatment period.

\section{Patient Data and Interventions}

Demographic information such as age, sex and pain duration were collected (Table 1). To investigate the therapeutic effectiveness of US, patients were randomly assigned (using a randomization table) into two groups to receive US and not (control). The random allocation sequence was generated and assigned to patients by two independent nurses in a different department. US was generated from an ultrasonic therapy instrument (model HB820D, Zefeng Medical Rehabilitation Equipment Co., Ltd, Changzhou, China) at an output of $45 \mathrm{~W}$ and frequency of $800 \mathrm{kHz}$. The frequency and output were based on the manufacturer's recommendations. US was applied by placing the probes $5 \mathrm{~cm}$ away from the temporomandibular joints (Figure 1). A treatment that contains three 5-minute blasts with a 2-minute interval between the blasts was applied once a day for 5 days in a week for 2 weeks. Patients in the control group received the same treatment without US. Patients who participated as controls were treated with various approaches after the experiments, including US and massage, based on each patient's selection.

\section{Outcome Assessment}

Pain was the primary outcome measure and temporomandibular functions were the secondary outcome measures. Before, 4 weeks and 6 months after the therapies, patients were evaluated for pain based on VAS that measures the pain on a 10-point scale with 0 corresponding to no pain and 10 to unbearable pain. ${ }^{23}$ Pain-free inter-incisal distance (IID) was measured using a digital caliper with a $0.01 \mathrm{~mm}$ precision. ${ }^{24}$ Briefly, participants were seated and asked to open their mouth as much as

Table I Baseline Characteristics of Patients

\begin{tabular}{|l|l|l|l|}
\hline Characteristics & Ultrasound & Control & $\boldsymbol{P}$ \\
\hline Patients, n & 80 & 80 & \\
Age, years & $35.8 \pm 9.7$ & $36.0 \pm 8.0$ & 0.519 \\
Pain duration, days & $74.3 \pm 16.5$ & $71.8 \pm 17.7$ & $0.51 \mathrm{I}$ \\
Affected side, n, right/left & $39 / 4 \mathrm{I}$ & $42 / 38$ & 0.316 \\
Sex, n, male/female & $43 / 37$ & $42 / 38$ & 0.215 \\
Diabetes, n & $\mathrm{II}$ & 13 & 0.415 \\
Hypertension, $\mathrm{n}$ & 16 & 14 & 0.312 \\
VAS & $4.90 \pm 1.83$ & $4.70 \pm 2.02$ & 0.636 \\
IID, cm & $2.73 \pm 0.38$ & $2.61 \pm 0.53$ & 0.422 \\
MM, cm & $5.76 \pm 0.60$ & $6.15 \pm 0.55$ & 0.843 \\
JN, dB & $3.20 \pm 0.63$ & $3.61 \pm 0.68$ & 0.921 \\
DI & $8.11 \pm 0.80$ & $8.20 \pm 0.77$ & $0.68 \mathrm{I}$ \\
\hline
\end{tabular}

Abbreviations: VAS, visual analog scale of pain; IID, inter-incisal distance; MM, mandibular movement; JN, jaw noise; DI, disability index. 


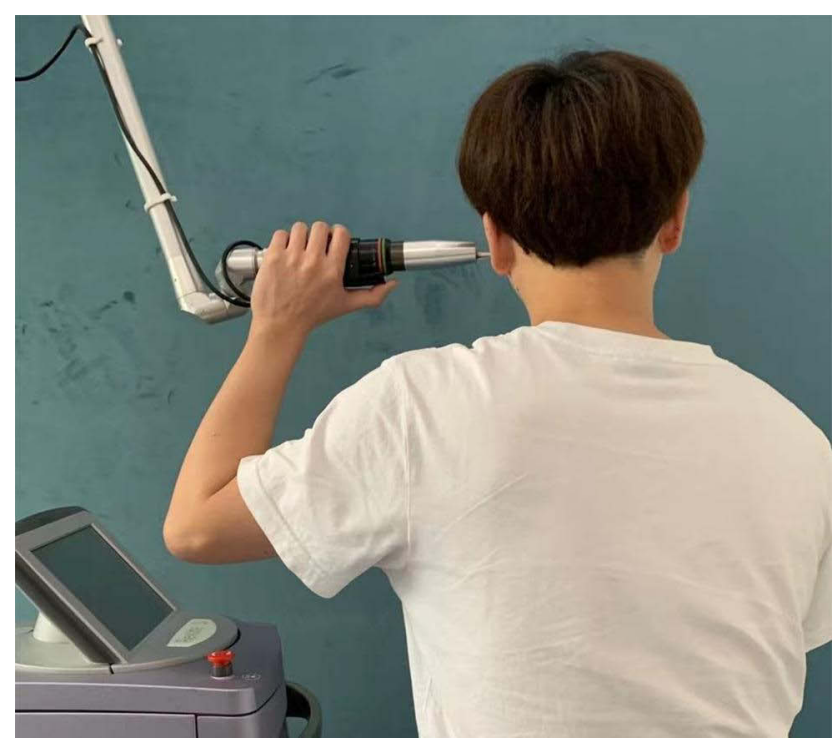

Figure I Treatment of patients with ultrasound from an ultrasonic therapy instrument.

possible without causing pain. At that limit, the distance between the upper and lower central incisors was measured. Other temporomandibular functions were assessed as described previously, ${ }^{25,26}$ including mandibular movement (MM), jaw noise (JN), and disability index (DI). The craniomandibular index (CMI) was calculated based on relevant examinations. ${ }^{26}$ The assessments were performed by physicians from a separate team who were blinded to patient's assignment and treatment.

\section{Statistical Analysis}

Data were expressed as mean \pm standard deviation and analyzed using Statistical Package for the Social Sciences (SPSS Inc., Chicago, IL, USA). The Wilcoxon rank test was used to compare intra-group differences for pain between pre-treatment and 4 weeks after treatment; Mann-Whitney rank test was conducted for comparing the intergroup difference. Within-group comparisons for pain-free IID were performed using paired sample t-tests. Independent t-tests were carried out for intergroup pain comparisons between pre-treatment and 4 weeks post-treatment. A value of $P<$ 0.05 was considered statistically significant.

\section{Results}

\section{Baseline Data}

Initially, 192 consecutive patients visiting our center were referred to participate the study. Thirty-two patients were excluded due to various personal reasons and inability to meet the inclusion criteria. A total of 160 patients were finally included and randomized to US and control groups, each consisting of 80 participants. Six people were lost in the follow-up and the remaining 154 patients were examined (Figure 2). Basic characteristics of the patients are summarized in Table 1 and there was no difference in those characteristics between the two groups, including gender, age, duration of disease, underlying diseases, jaw functions, and severity of TMD $(P>0.05)$.

\section{US Improved VAS, IID and Other Jaw Functions}

Four weeks and 6 months after US therapy, VAS, IID and other jaw functions such as JN and DI were significantly improved compared with before the therapies (Table 2). At 6 month follow-up, most of the function improvements were preserved although the results were slightly but insignificantly decreased when compared with the results at 4 weeks after the treatments. These were especially remarkable for VAS and JN. On other hand, most of these parameters were significantly deteriorated in control group at the two time points (Table 2).

\section{US Improved CMI and Had Lower Recurrence Rate}

Before the therapies, the Fricton's CMI measured for MM, $\mathrm{JN}$ and DI were not statistically different between the two groups (Table 3). Four weeks and 6 months after US treatments, these parameters were statistically better than before the treatments (Table 3). At 6 month follow-up, two patients were found to develop TMD again in the US group, although the overall severity of symptoms was less than what they had previously, before the therapies. The recurrence rate in the US group was $2.63 \%$ (Table 3 ).

\section{Discussion}

TMD impairs chewing, swallowing, and speaking. The main signs are pain, jaw noise, reduced range of motion, and reduced mandibular deviation. Therefore, the treatment of TMD patients has been attempted from multiple perspectives, including pharmacological and physical therapies. ${ }^{27,28}$ Although a number of methods are available, the rational selection of a treatment method is very important to achieve the best outcomes for patients. ${ }^{28,29}$ The patients in this study had relatively long TMD duration, and were likely to have slow responses to the therapy.

Recently, US has become increasingly popular as a physical treatment for a number of disorders. ${ }^{30,31}$ Our work 


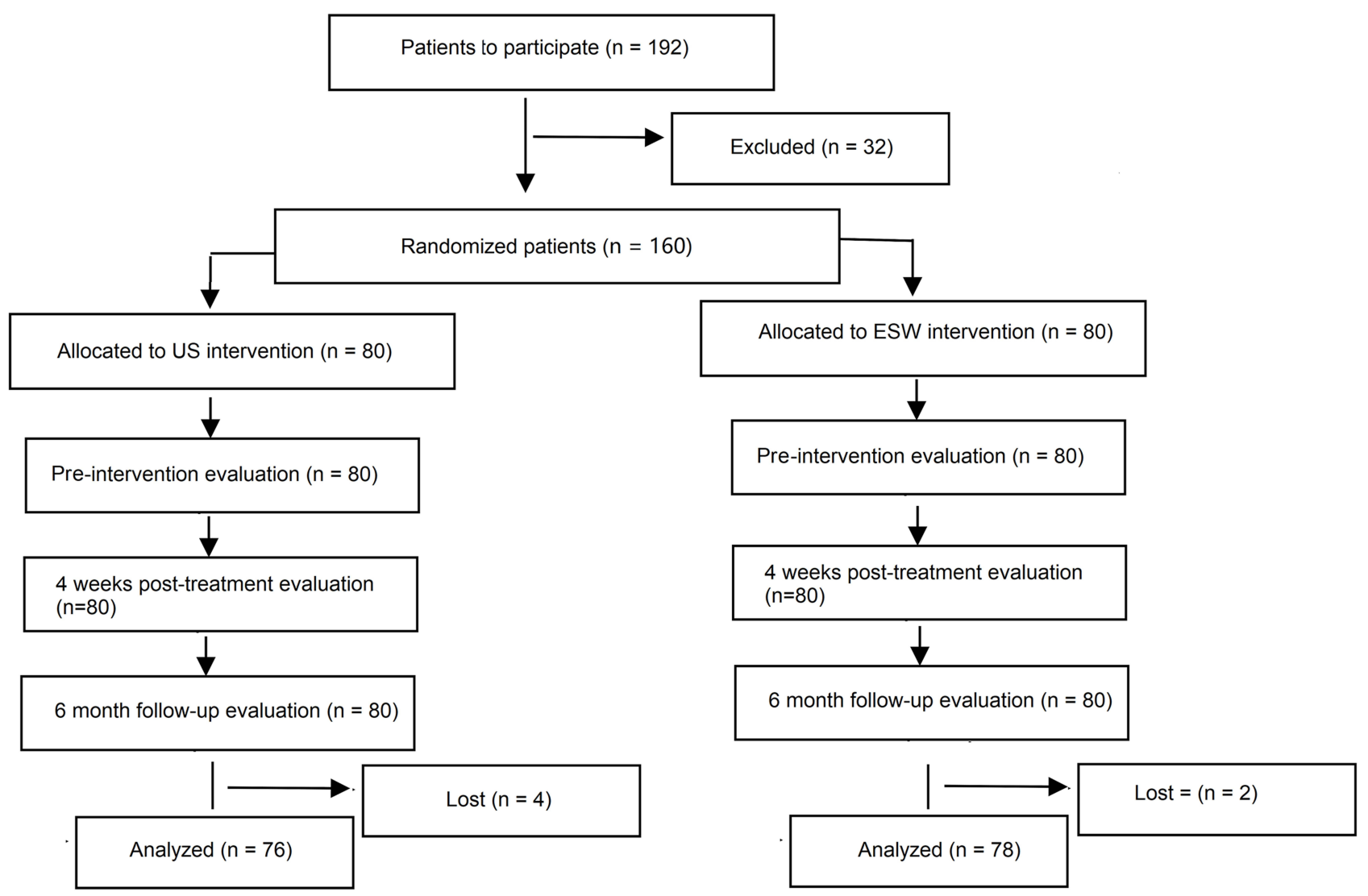

Figure 2 Diagram of patient selection, treatment and analysis.

showed that at the settings used in this study, US is effective in treating TMD, leading to improved VAS, IID and CIM indexes 4 weeks and 6 months after treatment. US consists of sound waves with frequencies higher than the upper audible limit of human hearing. Earlier studies showed that during the occurrence and development of TMD, cytokines such as IL-1, IL-6

Table 2 Pain and Jaw Functions of TMD Patients Before and After Therapy

\begin{tabular}{|c|c|c|c|c|c|}
\hline Variables & & & Ultrasound & Control & $P$ \\
\hline \multirow[t]{3}{*}{ VAS } & Before & & $4.90 \pm 1.83$ & $4.70 \pm 2.02$ & 0.636 \\
\hline & \multirow[t]{2}{*}{ After } & 4 weeks & $1.70 \pm 0.98 * *$ & $4.95 \pm 1.15$ & 0.023 \\
\hline & & 6 months & $1.90 \pm 0.78 * *$ & $5.05 \pm 1.05 *$ & 0.013 \\
\hline \multirow[t]{3}{*}{ IID, cm } & Before & & $1.66 \pm 0.60$ & $1.65 \pm 0.55$ & 0.614 \\
\hline & \multirow[t]{2}{*}{ After } & 4 weeks & $2.21 \pm 0.22 * *$ & $1.62 \pm 0.26$ & 0.032 \\
\hline & & 6 months & $2.26 \pm 0.21^{* *}$ & $1.63 \pm 0.23$ & 0.037 \\
\hline \multirow[t]{3}{*}{$\mathrm{JN}, \mathrm{dB}$} & Before & & $3.16 \pm 0.43$ & $3.11 \pm 0.38$ & 0.492 \\
\hline & \multirow[t]{2}{*}{ After } & 4 weeks & $2.07 \pm 0.3 I^{*}$ & $3.15 \pm 0.49$ & 0.045 \\
\hline & & 6 months & $2.17 \pm 0.2 I^{*}$ & $3.05 \pm 0.39$ & 0.047 \\
\hline \multirow[t]{3}{*}{ DI } & Before & & $8.91 \pm 1.80$ & $8.80 \pm 1.72$ & 0.198 \\
\hline & \multirow[t]{2}{*}{ After } & 4 weeks & $4.29 \pm 0.37 * *$ & $8.30 \pm 0.21$ & 0.027 \\
\hline & & 6 months & $4.19 \pm 0.47^{* *}$ & $8.90 \pm 0.41$ & 0.021 \\
\hline
\end{tabular}

Note: *, and ** denote $P<0.05$ and 0.01 , respectively, vs before therapy.

Abbreviations: VAS, visual analog scale of pain; IID, inter-incisal distance; MM, mandibular movement; JN, jaw noise; DI, disability index. 
Table 3 Fricton's Craniomandibular Indexes and Recurrence Rates of TMD Patients Before and After Therapy

\begin{tabular}{|c|c|c|c|c|c|}
\hline Variables & & & Ultrasound & Control & $P$ \\
\hline \multirow[t]{3}{*}{ IID, cm } & Before & & $5.66 \pm 0.60$ & $5.65 \pm 0.55$ & 0.914 \\
\hline & \multirow[t]{2}{*}{ After } & 4 weeks & $2.21 \pm 0.22^{* *}$ & $5.79 \pm 0.26$ & 0.012 \\
\hline & & 6 months & $2.26 \pm 0.21^{* *}$ & $6.99 \pm 0.23 *$ & 0.012 \\
\hline \multirow[t]{3}{*}{$\mathrm{JN}, \mathrm{dB}$} & Before & & $3.16 \pm 0.43$ & $3.11 \pm 0.38$ & 0.492 \\
\hline & \multirow[t]{2}{*}{ After } & 4 weeks & $2.07 \pm 0.31 *$ & $3.15 \pm 0.49$ & 0.015 \\
\hline & & 6 months & $2.17 \pm 0.21 *$ & $3.33 \pm 0.39$ & 0.015 \\
\hline \multirow[t]{3}{*}{ DI } & Before & & $8.91 \pm 1.80$ & $8.80 \pm 1.72$ & 0.198 \\
\hline & \multirow[t]{2}{*}{ After } & 4 weeks & $4.29 \pm 0.37 * *$ & $8.30 \pm 0.21$ & 0.021 \\
\hline & & 6 months & $4.19 \pm 0.47 * *$ & $8.90 \pm 0.41$ & 0.021 \\
\hline Recurrence at 6 months, $\mathrm{n}(\%)$ & & & $2(2.63)$ & $N / A$ & \\
\hline
\end{tabular}

Note: *, and ** denote $P<0.05$ and 0.01 , respectively vs before therapy

Abbreviations: VAS, visual analog scale of pain; IID, inter-incisal distance; MM, mandibular movement; JN, jaw noise; DI, disability index.

and TNF- $\alpha$ are involved in the inflammation of synovium, leading to the destruction of articular cartilage and excessive apoptosis of chondrocytes in the soft tissue of bone and joint as a result of increased NO content and the imbalance of local metabolism in the joint. ${ }^{32-34}$ US has been shown to able to reduce excessive cytokine content in the articular fluid and the apoptosis of chondrocytes. It promotes the proliferation of articular cartilage to repair cartilage defects, and inhibits the secretion of inflammatory cytokines. ${ }^{35,36}$ In animal models, low intensity pulsed ultrasound (LIPUS) was able to enhance mandibular growth ${ }^{37,38}$ and modify the growth of the mandible, ${ }^{39}$ providing additional support of US inducedmandible modification that might contribute to the observed therapeutic effect.

The results of this study showed that the VAS scores decreased after US treatment, and the decreases were retained within the 6 month follow-up period, suggesting that the treatments are effective in alleviating pain in the long term. Furthermore, pain-free IID increased after the treatment, further demonstrating that US is effective for TMD treatment. The beneficial effect of US may be associated with the effect of micro-destruction, ${ }^{40,41}$ which is likely to result in micro-tears of nonvascularized or scantily vascularized tissues, and thus stimulate revascularization by the local release of growth factors and mobilization of stem cells, leading to increased blood supply to the tissue, ${ }^{40,42}$ although more studies are needed to investigate the mechanisms that reduce the muscle tone in spasticity. ${ }^{43}$
In addition to pain and IID, US treatment also resulted in significant improvement of jaw functions as measured by CIM indexes, as the improvements were also persistent during the follow-up period. For non-surgical treatment, recurrence is often a concern. ${ }^{44}$ Our examinations showed that the recurrence of TMD in the treated patients is low. However, it is unclear if more patients would develop TMD in the longer run.

Although our study provides valuable information regarding US in treating TMD, there are limitations. It was a single-center study with a limited number of participants. Patients were not stratified for treatments at different doses and were not followed up for more than 6 months. Further studies are needed to validate our results with more patients to optimize the treatment settings and doses for better outcomes.

Taken together, our study indicates that US is effective to treat TMD and could substantially decrease pain and improve IID and jaw functions. The therapeutic effect is persistent in a follow-up period of 6 months, with less than $3 \%$ recurrence rate after US treatment. Therefore, US may be recommended for TMD treatment.

\section{Clinical Messages}

- TMDs are one of the most common causes of pain in the mouth and face and affect millions of people.

- The finding provides a new clinical tool to manage the disease.

- Ultrasound is found to be effective in relieving pain and improving jaw functions for TMD patients. 


\section{Funding}

There is no funding to report.

\section{Disclosure}

The authors declare that they have no competing interests.

\section{References}

1. Durham J, Newton-John TR, Zakrzewska JM. Temporomandibular disorders. BMJ. 2015;350(9):h1154. doi:10.1136/bmj.h1154

2. Zakrzewska JM. Temporomandibular disorders, headaches and chronic pain. J Pain Palliat Care Pharmacother. 2015;29(1):61-3; discussion 3. doi:10.3109/15360288.2014.1003678

3. Schiffman E, Ohrbach R, Truelove E, et al. Diagnostic Criteria for Temporomandibular Disorders (DC/TMD) for clinical and research applications: recommendations of the international RDC/TMD consortium network and orofacial pain special interest groupdagger. $J$ Oral Facial Pain Headache. 2014;28(1):6-27. doi:10.11607/jop.1151

4. De Leeuw R, Klasser GD. Orofacial Pain: Guidelines for Assessment, Diagnosis, and Management. Chicago: Quintessence; 2008.

5. Kothari SF, Baad-Hansen L, Oono Y, Svensson P. Somatosensory assessment and conditioned pain modulation in temporomandibular disorders pain patients. Pain. 2015;156(12):2545-2555. doi:10.1097/ j.pain.0000000000000325

6. Benoliel R, Svensson P, Heir GM, et al. Persistent orofacial muscle pain. Oral Dis. 2011;17(Suppl 1):23-41. doi:10.1111/j.16010825.2011.01790.x

7. Shephard MK, Macgregor EA, Zakrzewska JM. Orofacial pain: a guide for the headache physician. Headache. 2014;54(1):22-39. doi:10.1111/head.12272

8. Kotiranta U, Forssell H, Kauppila T. Painful temporomandibular disorders (TMD) and comorbidities in primary care: associations with pain-related disability. Acta Odontol Scand. 2019;77(1):22-27. doi:10.1080/00016357.2018.1493219

9. Almoznino G, Zini A, Zakuto A, et al. Oral health-related quality of life in patients with temporomandibular disorders. J Oral Facial Pain Headache. 2015;29(3):231-241. doi:10.11607/ofph.1413

10. Miernik M, Wieckiewicz M, Paradowska A, Wieckiewicz W. Massage therapy in myofascial TMD pain management. Adv Clin Exp Med. 2012;21(5):681-685.

11. Morell GC. Manual therapy improved signs and symptoms of temporomandibular disorders. Evid Based Dent. 2016;17(1):25-26. doi:10.1038/sj.ebd.6401155

12. Bevilaqua-Grosso D, Monteiro-Pedro V, Guirro RR, Berzin F. A physiotherapeutic approach to craniomandibular disorders: a case report. J Oral Rehabil. 2002;29(3):268-273. doi:10.1046/j.13652842.2002.00832.x

13. Sanders C, Liegey-Dougall A, Haggard R, et al. Temporomandibular disorder diagnostic groups affect outcomes independently of treatment in patients at risk for developing chronicity: a 2-year follow-up study. J Oral Facial Pain Headache. 2016;30(3):187-202. doi:10.11607/ofph.1613

14. Zhou FH, Zhao HY. [Acupuncture and ultrasound therapy for temporomandibular disorders]. Di Yi Jun Yi Da Xиe Xиe Bao. 2004;24 (6):720-721. [Chinese]

15. Kraus M, Reinhart E, Krause H, Reuther J. [Low energy extracorporeal shockwave therapy (ESWT) for treatment of myogelosis of the masseter muscle]. Mund Kiefer Gesichtschir. 1999;3(1):20-23. doi:10.1007/s100060050087 [Chinese]

16. Tanaka E, Liu Y, Xia L, et al. Effectiveness of low-intensity pulsed ultrasound on osteoarthritis of the temporomandibular joint: a review. Ann Biomed Eng. 2020;48(8):2158-2170. doi:10.1007/s10439-02002540-x
17. Yang T, Liang C, Chen L, Li J, Geng W. Low-intensity pulsed ultrasound alleviates hypoxia-induced chondrocyte damage in temporomandibular disorders by modulating the hypoxia-inducible factor pathway. Front Pharmacol. 2020;11:689. doi:10.3389/fphar.2020. 00689

18. Notarnicola A, Moretti B. The biological effects of extracorporeal shock wave therapy (eswt) on tendon tissue. Muscles Ligaments Tendons J. 2012;2(1):33-37.

19. Mattyasovszky SG, Langendorf EK, Ritz U, et al. Exposure to radial extracorporeal shock waves modulates viability and gene expression of human skeletal muscle cells: a controlled in vitro study. J Orthop Surg Res. 2018;13(1):75. doi:10.1186/s13018-018-0779-0

20. Slavich M, Pizzetti G, Vella AM, et al. Extracorporeal myocardial shockwave therapy; a precious blast for refractory angina patients. Cardiovasc Revasc Med. 2018;19(3Pt A):263-267. doi:10.1016/j. carrev.2017.09.018

21. Brosseau L, Casimiro L, Robinson V, et al. Therapeutic ultrasound for treating patellofemoral pain syndrome. Cochrane Database Syst Rev. 2001;(4):CD003375.

22. Schiffman EL, Truelove EL, Ohrbach R, et al. The research diagnostic criteria for temporomandibular disorders. I: overview and methodology for assessment of validity. J Orofac Pain. 2010;24 (1):7-24.

23. Heller GZ, Manuguerra M, Chow R. How to analyze the visual analogue scale: myths, truths and clinical relevance. Scand J Pain. 2016;13(1):67-75. doi:10.1016/j.sjpain.2016.06.012

24. Walker N, Bohannon RW, Cameron D. Discriminant validity of temporomandibular joint range of motion measurements obtained with a ruler. J Orthop Sports Phys Ther. 2000;30(8):484-492. doi:10.2519/jospt.2000.30.8.484

25. Fricton JR, Schiffman EL. Reliability of a craniomandibular index. $J$ Dent Res. 1986;65(11):1359-1364.

26. Fricton JR, Schiffman EL. The craniomandibular index: validity. $J$ Prosthet Dent. 1987;58(2):222-228. doi:10.1016/0022-3913(87) 90181-8

27. Liu F, Steinkeler A. Epidemiology, diagnosis, and treatment of temporomandibular disorders. Dent Clin North Am. 2013;57(3):465-479. doi:10.1016/j.cden.2013.04.006

28. Gauer RL, Semidey MJ. Diagnosis and treatment of temporomandibular disorders. Am Fam Physician. 2015;91(6):378-386.

29. Zhao Y. Treatment of temporomandibular joint disorders using acupuncture combined with Chinese and Western medicine. Chin J Trad Chin Med. 2011;29(7):1681-1682.

30. Draper DO. Facts and misfits in ultrasound therapy: steps to improve your treatment outcomes. Eur $J$ Phys Rehabil Med. 2014;50 (2):209-216.

31. Kubot A, Grzegorzewski A, Synder M, Szymczak W, Kozlowski P. Radial extracorporeal shockwave therapy and ultrasound therapy in the treatment of tennis elbow syndrome. Ortop Traumatol Rehabil. 2017;19(5):415-426. doi:10.5604/01.3001.0010.5821

32. Cheng J, Wang Y, Wang Z, Yang M, Wu Y. Differential regulation of proteoglycan-4 expression by IL-1alpha and TGF-betal in rat condylar chondrocytes. Tohoku J Exp Med. 2010;222(3):211-218. doi:10.1620/tjem.222.211

33. Kou XX, Wu YW, Ding Y, et al. 17beta-estradiol aggravates temporomandibular joint inflammation through the NF-kappaB pathway in ovariectomized rats. Arthritis Rheum. 2011;63(7):1888-1897. doi:10.1002/art.30334

34. Jiao K, Niu LN, Wang MQ, et al. Subchondral bone loss following orthodontically induced cartilage degradation in the mandibular condyles of rats. Bone. 2011;48(2):362-371. doi:10.1016/j.bone.2010.09.010

35. Kim YH, Bang JI, Son HJ, et al. Protective effects of extracorporeal shockwave on rat chondrocytes and temporomandibular joint osteoarthritis; preclinical evaluation with in vivo $(99 \mathrm{~m}) \mathrm{Tc}-\mathrm{HDP}$ SPECT and ex vivo micro-CT. Osteoarthritis Cartilage. 2019;27(11):1692-1701. doi:10.1016/j.joca.2019.07.008 
36. Hazan-Molina H, Reznick AZ, Kaufman H, Aizenbud D. Assessment of IL-1beta and VEGF concentration in a rat model during orthodontic tooth movement and extracorporeal shock wave therapy. Arch Oral Biol. 2013;58(2):142-150. doi:10.1016/j.archoralbio.2012.09.012

37. Khan I, El-Kadi AO, El-Bialy T. Effects of growth hormone and ultrasound on mandibular growth in rats: microCT and toxicity analyses. Arch Oral Biol. 2013;58(9):1217-1224. doi:10.1016/j. archoralbio.2013.03.018

38. Sasaki K, Motoyoshi M, Horinuki E, Arai Y, Shimizu N. Effect of low-intensity pulsed ultrasound (LIPUS) on mandibular condyle growth in rats analyzed with micro-CT. J Oral Sci. 2016;58 (3):415-422. doi:10.2334/josnusd.16-0010

39. El-Bialy T, Hassan A, Albaghdadi T, Fouad HA, Maimani AR. Growth modification of the mandible with ultrasound in baboons: a preliminary report. Am J Orthod Dentofacial Orthop. 2006;130 (4):435 e7-14. doi:10.1016/j.ajodo.2006.01.025

40. Contaldo C, Högger DC, Khorrami Borozadi M, et al. Radial pressure waves mediate apoptosis and functional angiogenesis during wound repair in ApoE deficient mice. Microvasc Res. 2012;84 (1):24-33. doi:10.1016/j.mvr.2012.03.006
41. Wang C-J, Wang F-S, Yang KD, et al. Shock wave therapy induces neovascularization at the tendon-bone junction. A study in rabbits. J Orthop Res. 2003;21(6):984-989. doi:10.1016/S0736-0266(03) 00104-9

42. Mariotto S, Cavalieri E, Amelio E, et al. Extracorporeal shock waves: from lithotripsy to anti-inflammatory action by NO production. Nitric Oxide. 2005;12(2):89-96. doi:10.1016/j.niox.2004.12.005

43. Park D-S, Kwon DR, Park G-Y, Lee MY. Therapeutic effect of extracorporeal shock wave therapy according to treatment session on gastrocnemius muscle spasticity in children with spastic cerebral palsy: a Pilot Study. Ann Rehabil Med. 2015;39(6):914-921. doi:10.5535/arm.2015.39.6.914

44. Burger M, Dreyer D, Fisher RL, et al. The effectiveness of proprioceptive and neuromuscular training compared to bracing in reducing the recurrence rate of ankle sprains in athletes: a systematic review and meta-analysis. J Back Musculoskelet Rehabil. 2018;31 (2):221-229. doi:10.3233/BMR-170804

\section{Publish your work in this journal}

The Journal of Pain Research is an international, peer reviewed, open access, online journal that welcomes laboratory and clinical findings in the fields of pain research and the prevention and management of pain. Original research, reviews, symposium reports, hypothesis formation and commentaries are all considered for publication. The manuscript management system is completely online and includes a very quick and fair peer-review system, which is all easy to use. Visit http:// www.dovepress.com/testimonials.php to read real quotes from published authors. 